\title{
IMPAIRMENT OF THE CHONDROGENIC PHASE OF ENDOCHONDRAL OSSIFICATION IN VIVO BY INHIBITION OF CYCLOOXYGENASE-2
}

\author{
M.P.F. Janssen ${ }^{1, \$}$, M.M.J. Caron ${ }^{1, *,}$, B. van Rietbergen ${ }^{1,2}$, D.A.M. Surtel ${ }^{1}$, L.W. van Rhijn ${ }^{1}$, T.J.M. Welting ${ }^{1}$ \\ and P.J. Emans ${ }^{1}$ \\ ${ }^{1}$ Laboratory for Experimental Orthopaedics, Department of Orthopaedic Surgery, CAPHRI Care and \\ Public Health Research Institute, Maastricht University Medical Centre, PO Box 5800, \\ 6202 AZ Maastricht, the Netherlands \\ ${ }^{2}$ Orthopaedic Biomechanics, Department of Biomedical Engineering, Eindhoven University of \\ Technology, PO Box 513, 5600 MB Eindhoven, the Netherlands \\ $\S$ These authors contributed equally
}

\begin{abstract}
Many studies have reported on the effects of cyclooxygenase-2 (COX-2) inhibition on osteogenesis. However, far less is known about the effects of COX-2 inhibition on chondrogenic differentiation. Previous studies conducted by our group show that COX-2 inhibition influences in vitro chondrogenic differentiation. Importantly, this might have consequences on endochondral ossification processes occurring in vivo, such as bone fracture healing, growth plate development and ectopic generation of cartilage. The goal of our study was to investigate, in vivo, the effect of COX-2 inhibition by celecoxib on the cartilaginous phase of three different endochondral ossification scenarios.

$10 \mathrm{mg} / \mathrm{kg} / \mathrm{d}$ celecoxib or placebo were orally administered for $25 \mathrm{~d}$ to skeletally-immature New Zealand White rabbits ( $n=6$ per group). Endochondral ossification during fracture healing of a non-critical size defect in the ulna, femoral growth plate and ectopically-induced cartilaginous tissue were examined by radiography, micro-computed tomography $(\mu-C T)$, histology and gene expression analysis.

Celecoxib treatment resulted in delayed bone fracture healing, alterations in growth plate development and progression of mineralisation. In addition, chondrogenic differentiation of ectopically-induced cartilaginous tissue was severely impaired by celecoxib. In conclusion, we found that celecoxib impaired the chondrogenic phase of endochondral ossification.
\end{abstract}

Keywords: Endochondral ossification, fracture healing, growth plate development, nonsteroidal antiinflammatory drugs, cyclooxygenase 2, celecoxib, chondrogenic differentiation.

*Address for correspondence: Marjolein M.J. Caron, PhD, Laboratory for Experimental Orthopaedics, Department of Orthopaedic Surgery, CAPHRI Care and Public Health Research Institute, Maastricht University Medical Centre, PO Box 5800, 6202 AZ Maastricht, the Netherlands.

Telephone: +31 $433884153 \quad$ Email: marjolein.caron@maastrichtuniversity.nl

\section{Introduction}

Bone formation occurs following two mechanisms: intramembranous ossification and endochondral ossification (EO) (Marsell and Einhorn, 2011). During intramembranous ossification, mesenchymal stem cells directly differentiate into osteocytes to form new bone without formation of cartilaginous tissue (Kronenberg, 2003; Thompson et al., 2002). This process mainly takes place during cranial bone formation and healing of highly-stabilised fractures (Thompson et al., 2002). The other important mechanism is EO, which is responsible for normal long bone formation in the growth plates (Kronenberg, 2003). Growth plates are populated by highly proliferative chondrocytes, which differentiate into mineralising hypertrophic chondrocytes that either die from apoptosis or transdifferentiate into osteoblasts (Park et al., 2015; Yang et al., 2014; Zhou et al., 2014). The remaining mineralised extracellular matrix (ECM) provides a scaffold for osteoblasts and osteoclasts to adhere and remodel, setting the stage for bone apposition and, thus, longitudinal bone growth and limb development (Kronenberg, 2003; Mackie et al., 2008).

Fracture healing through EO starts with the formation of a haematoma in which mesenchymal stem cells condense and subsequently differentiate following the chondrogenic lineage towards chondrocytes. Then, the chondrocytes become 
hypertrophic and direct the formation of mineralised matrix, promote angiogenesis and finally undergo apoptosis (Marsell and Einhorn, 2011). Then, in a similar way to the growth plate, the leftover mineralised matrix is invaded by osteoblasts and osteoclasts, which will remodel the matrix into woven bone. The woven bone is gradually replaced by lamellar bone and the fracture is united. During the final phase, the newly-formed bone is remodelled to its original shape (Hadjiargyrou and O'Keefe, 2014; Kronenberg, 2003). In addition, cartilaginous tissue, ectopically generated for the purpose of cartilage repair, forms from progenitor cells by an EO process (Caldwell and Wang, 2014; Caron et al., 2014). One of the main problems in many cartilage repair strategies is the premature hypertrophic differentiation of the generated cartilage (Dickhut et al., 2009; van Osch et al., 2009).

Impaired endochondral ossification can lead to various problems. During EO, disturbances of the growth plate might lead to abnormal skeletal development. Most intensively investigated problems of EO during fracture healing are delayed union and non-union of fractures (Calori et al., 2007; Santolini et al., 2015). In contrast, too active EO can cause undesirable effects i.e. heterotopic ossification after joint arthroplasty or trauma (Spinarelli et al., 2011) and intralesional ossification in cartilage repair surgery (Bouwmeester et al., 1997; Brown et al., 2004).

To date, the exact biomolecular mechanisms involved in EO are still not fully understood. We only begin to understand the spatiotemporal roles and effects of morphogens or medications on chondrogenic differentiation during EO. However, detailed knowledge on timing and (spatiotemporal) concentration of morphogens and/or medications during chondrogenic differentiation of progenitor cells is important for correct formation of cartilage and bone tissues (Emans et al., 2012).

Non-steroidal anti-inflammatory drugs (NSAIDs) are widely used systemic inhibitors of inflammatory prostaglandin production induced by cyclooxygenases (COX-1 and COX-2) (Brooks et al., 1999). NSAIDs have inhibitory effects on fracture healing, which mainly depends on the dose and duration of the treatment (Gerner and O'Connor, 2008; Geusens et al., 2013). In addition, most studies that ascribed a role for COX-2 in bone fracture healing, focused on osteogenesis (Lau et al., 2013; O'Connor and Lysz, 2008; Simon et al., 2002; Simon and O'Connor, 2007; Zhang et al., 2011) and left chondrogenesis unstudied. Therefore, the potential effect of COX-2 inhibitors on the chondrogenic part of EO is incompletely understood. Chondrogenic differentiation precedes the ossification phase during EO and the limiting effect of COX-2 inhibitors on EO may also be ascribed to impaired chondrogenic differentiation of the mesenchymal progenitor cells.

Our previous study shows that specific COX2 inhibitors decrease chondrocyte hypertrophic differentiation in the growth plate during the chondrogenic phase of EO (Welting et al., 2011). However, it is still unknown whether this action is specific for the growth plate or whether it affects the cartilaginous phase of endochondral ossification in a broader way. To further extend our knowledge on the influence of the COX-2 inhibitor celecoxib on the cartilaginous phase of $\mathrm{EO}$, we tested it in three different in vivo compartments of the same rabbit. We studied EO during fracture healing of a non-critical size defect in the ulnae, in the growth plate and in ectopically-induced cartilaginous tissue (Emans et al., 2007; Emans et al., 2010).

\section{Materials and Methods}

\section{Experimental design and animal model}

12 female, skeletally-immature (107 d old, 1.8 kg), specific-pathogen-free (SPF) New Zealand White (NZW) rabbits were used. The experiment was approved by the Maastricht University animal ethical committee (DEC 2010-027). Sample size was calculated according to the formula of L. Sachs (Sachs, 2004)

$$
\begin{gathered}
n=(\text { expected standard deviation/expected } \\
\text { effect size })^{2} \times 15.7
\end{gathered}
$$

and 6 animals per group were needed. Animals were randomly assigned to the treatment or control group. Throughout the experiment, animals were housed in groups under standard conditions with ad libitum access to water and food and $12 \mathrm{~h}$ of light each day. Animal well-being and behaviour (score in response to stimuli, back arch, twitch, wincing, posture, self-care, condition of skin, mobility, limb loading, difficulties in respiration/breathing, dehydration or undernourishment symptoms, colour of the mucous membranes and extremities, oedema/swelling/cold feeling and other notable abnormalities) were checked daily. $10 \mathrm{mg} / \mathrm{kg}$ celecoxib (Pfizer, New York, NY, USA) in $1 \mathrm{~mL}$ of Critical Care ${ }^{\circledR}$ paste (Oxbow Animal Health, Murdock, NE, USA) were administered orally to the treatment group $(n=6)$, on a daily basis from day 0 . Control animals $(n=6)$ received exclusively $1 \mathrm{~mL}$ of Critical Care ${ }^{\circledR}$ paste. To label tissue mineralisation, $25 \mathrm{mg} / \mathrm{kg}$ calcein green fluorochrome (Sigma-Aldrich, St. Louis, MO, USA) was injected subcutaneously. Calcein green is a marker of mineralisation that, when injected, is incorporated in newly-formed bone for 24-36 h, while the unincorporated label is excreted by the kidneys within several hours (van Gaalen et al., 2010). In previous studies, we show that mineralisation during EO occurs about two weeks after initialisation of EO (Emans et al., 2005; Emans et al., 2007; Welting et al., 2011); therefore, the injection was performed at day 14 of the experiment (11 d before sacrifice). After $25 \mathrm{~d}$, rabbits were euthanised by an overdose of intravenous pentobarbital. During further processing, the specimens were coded and, thus, the researchers were blinded to the treatment received. 


\section{Surgery}

Non-critical sized defect

At day 0, a $5 \mathrm{~mm}$ non-critical size defect was created in the left ulna of all rabbits (Frame, 1980). Animals were anaesthetised by isoflurane inhalation. The skin was opened over the ulnae and the diaphysis approached. A $5 \mathrm{~mm}$ defect was created $25 \mathrm{~mm}$ above the carpal joint in the exposed ulnae using an oscillating saw, which was cooled by irrigation fluid. Due to the fibro-osseous union of ulna and radius proximal and distal to the surgical site, no fixation of the bone fragments was required (Matos et al., 2008). Muscles were replaced over the defect and the incision was closed layer by layer with Vicryl Rapide ${ }^{\mathrm{TM}}$ 4-0 absorbable sutures (Ethicon, Kirkton, Scotland). The animals were allowed full weight bearing directly after surgery.

\section{Growth plates}

The growth plate of the distal femur was examined. No surgery involving the growth plates was performed, no surgery was performed on the femur and the surgery of the tibia was equal in both groups and distal to the tibial growth plate, therefore, it was expected that surgery did not influence the growth plate of the distal femur.

\section{Periosteal endochondral ossification}

During the same surgical procedure when the non-critical size defect was created, we used the method described by Emans and colleagues, for ectopically-inducing cartilage formation, in which a subperiosteal space is created to induce periosteal endochondral ossification (PEO) (Emans et al., 2007; Emans et al., 2010). PEO was induced on both tibia, as described in literature, with minor modifications (Emans et al., 2007; Emans et al., 2010). The skin was opened over the upper medial side of the tibia, the pes anserinus was identified and the periosteum was incised just medially of the pes anserinus, leaving the semitendinosus tendon untouched. The periosteum was elevated proximally with a probe and $0.2 \mathrm{~mL}$ of a $2 \%(\mathrm{w} / \mathrm{v})$ agarose-based gel were injected between the bone and periosteum. The $2 \%(\mathrm{w} / \mathrm{v})$ agarose solution was prepared by dissolving $2 \mathrm{~g}$ of ultra-pure low-melting agarose granules (Cat no: 10975035, Lot No: MO91807; Invitrogen, Carlsbad, CA, USA) in $100 \mathrm{~mL}$ of $0.9 \% \mathrm{NaCl}$, followed by steam-sterilisation. The preparation was warmed to $40{ }^{\circ} \mathrm{C}$ in a water bath to liquefy it prior to use. Next, gelation was accelerated by cooling the PEO location with $5{ }^{\circ} \mathrm{C}$ sterile $0.9 \%$ $\mathrm{NaCl}$. Finally, the wound was closed in separate layers with Vicryl Rapide ${ }^{\mathrm{TM}}$ 4-0 absorbable sutures (Ethicon, Kirkton, Scotland). This procedure was repeated on the contra-lateral tibia (Emans et al., 2007; Emans et al., 2010).

\section{Prostaglandin $\mathrm{E}_{2}$ levels}

To confirm COX-2 inhibition by celecoxib, we determined prostaglandin $\mathrm{E}_{2}\left(\mathrm{PGE}_{2}\right)$ levels in blood plasma at day 0 and at sacrifice by standardised enzyme immunoassay (EIA) analysis (Cayman Chemicals, Ann Arbor, MI, USA). Briefly, blood was drawn at day 0 and just before sacrifice and centrifuged at $370 \times g$ for $5 \mathrm{~min}$. The blood plasma was used to perform an EIA for detection of $\mathrm{PGE}_{2}$ levels.

\section{Radiography}

Directly after sacrifice, plain radiographs of the ulnae were obtained with a mammography unit (Philips BV25; Philips, Eindhoven, the Netherlands) to determine the radiologic stage of fracture healing. Bone healing was scored according to the Lane and Sandhu radiological scoring system (Lane and Sandhu, 1987). To determine formation and mineralisation of PEO tissue, also plain radiographs of the tibia were obtained, taking care of positioning the tibia in such way that the site of PEO was visible on the radiograph.

\section{$\mu-\mathrm{CT}$}

After dissection of the leg, high-resolution images of the fracture region of all 12 affected ulnas (6 per group) were taken using a micro-computed tomography ( $\mu$ $\mathrm{CT}$ ) scanner ( $\mu$-CT80; Scanco Medical, Bruettisellen, Switzerland) at $55 \mathrm{kV}$. In the fracture region, the scan length was approximately $21 \mathrm{~mm}$ and the resolution was set to $36 \mu \mathrm{m}$. Based on these images, micro-finite element analyses (FEA) were performed to quantify fracture consolidation, by using an approach similar to that described by Shefelbine et al. (2005). First, the resolution was reduced to $108 \mu \mathrm{m}$ and a section of $14 \mathrm{~mm}$ in length, centred on the defect, was selected. Second, a two-level thresholding approach was used to identify three different tissue types based on the Houndsfield unit (HU): cartilaginous tissue (HU: 1000-1999), low-mineralised bone (HU: 2000-2999) and high-mineralised bone ( $\mathrm{HU} \geq 3000)$. Material properties were assigned depending on tissue type, with a Young's modulus of $1 \mathrm{MPa}$ for cartilaginous tissue, $5 \mathrm{GPa}$ for low-mineralised bone and $20 \mathrm{GPa}$ for high-mineralised bone. The Poisson's ratio was set to 0.3 for all tissues. Boundary conditions were applied to represent an axial compression test, an axial torsion test and bending tests in two orthogonal directions. Then, for each test the stiffness of the scanned region was determined (units: $\mathrm{N} / \mathrm{mm}$ for the compression tests and $\mathrm{Nmm} / \mathrm{rad}$ for the torsion/bending tests) (Isaksson et al., 2009; van Rietbergen et al., 1998).

\section{Histology and image analysis}

Non-critical size defect

The left ulnae were isolated and fixed in $4 \%$ formalin. After the tissue was fixed, the ulnae were gradually embedded in poly(methyl methacrylate) (PMMA) (Technovit 9100; Heraeus Kulzer, Hanau, Germany). After complete polymerisation, $50 \mu \mathrm{m}$-sagittal sections were cut using a saw microtome (SP1600; Leica, Wetzlar, Germany). Prior to the cutting of each section, a vonKossa/thionine or Masson-Goldner trichrome (Carl Roth $\mathrm{GmbH}$, Karlsruhe, Germany) staining was performed to visualise different tissue 
types (Bulstra et al., 1993). Sections were stained for 10 min with $1 \%$ silver nitrate $\left(\mathrm{AgNO}_{3} ; \mathrm{VWR}\right.$ Prolabo, Amsterdam, the Netherlands) and for $30 \mathrm{~s}$ with $5 \%$ sodium thiosulphate $\left(\mathrm{Na}_{2} \mathrm{~S}_{2} \mathrm{O}_{3} ; \mathrm{VWR}\right.$ Prolabo), rinsed with tap water for $5 \mathrm{~min}$ and finally stained for $10 \mathrm{~min}$ with a $0.25 \%$ thionine solution. The Masson-Goldner trichrome staining was performed according to the manufacturers' protocol. Sections were scored using a modified version of Heiple histologic fracture scoring system (Heiple et al., 1987).

\section{Femoral growth plates}

The left distal femora were isolated and fixed in $4 \%$ formalin (VWR Prolabo). Next, the femora were gradually embedded in PMMA (Technovit 9100; Heraeus Kulzer). After complete polymerisation, $50 \mu \mathrm{m}$-thick sections were cut in the sagittal plane between the condyles, in the anatomical middle of the femur, using a saw microtome (SP1600; Leica). Femora were positioned perpendicular to the microtome saw to obtain reproducible sections and to prevent false measurements due to skewness. Prior to sectioning, haematoxylin/eosin (H\&E; Dako, Troy, MI, USA) or no staining was applied by adding acid alcohol for $10 \mathrm{~min}, 0.6 \%$ haematoxylin for $10 \mathrm{~min}$, rinsing for $10 \mathrm{~min}$ with tap water and adding $0.2 \%$ eosin for $5 \mathrm{~min}$. Then, the H\&E stained sections were further processed for microscopical analysis, using a Zeiss Axioscope A.1 microscope (Zeiss, Oberkochen, Germany), with AxioVision 4.8 software. To prevent skew measurements and improve reproducibility, growth plate sections were placed in a way that the growth plate was aligned horizontally. Then, image frames were standardised to a width of $5.0 \mathrm{~mm}$ $(2.5 \mathrm{~mm}$ left and $2.5 \mathrm{~mm}$ right of the anatomical middle of the section). With a custom-written script in MatLab software (MathWorks, Natick, MA, USA), the average height of the proliferative and hypertrophic zone of each growth plate was determined.

The unstained sections were processed using a Leica microscope (DM RD; Leica), taking three images for each section with normal light and with filtered light, to assess the calcein green injected. Images were obtained and processed with Leica IM50 software. The three separate colour channels of the RGB images were combined with Adobe Photoshop CS3 software to create one image. Measurements on all sections were taken with AxioVision 4.8 software and a custom-written script in MatLab (the software was calibrated before measurements). The surface area between the mineralisation front at day 14 (calcein green front) and at day 25 (status at sacrifice) was measured in a box with a standardised width of $8.0 \mathrm{~mm}$. By dividing the surface area (in $\mu \mathrm{m}^{2}$ ) by the width of $8.0 \mathrm{~mm}$, the total growth after incorporation was calculated for both groups.

\section{Periosteal endochondral ossification}

Tibiae were isolated, fixed in $4 \%$ formalin and decalcified for 3 weeks in $0.5 \mathrm{M}$ ethylene diaminetetraacetic acid (EDTA, VWR Prolabo) $\mathrm{pH}$ 7.8. An additional brief $(20 \mathrm{~h})$ decalcification step was performed using $1: 5$ diluted Shandon ${ }^{\mathrm{TM}}$ TBD-1 ${ }^{\mathrm{TM}}$ Decalcifier (Thermo Fisher Scientific, Waltham, MA, USA). Next, the tibiae showing PEO were dehydrated with increasing concentration of ethanol and embedded in paraffin wax. Starting from the centre, where PEO occurred, $5 \mu \mathrm{m}$-thick sections were cut. Tissue sections were stained with safranin O/fast green (both from Sigma-Aldrich). Slides were deparaffinised and rehydrated using standard protocols. Proteoglycans were stained with $0.1 \%$ safranin $\mathrm{O}$ and counterstained with $0.1 \%$ fast green. Stained sections were dehydrated and mounted with Histomount (Thermo Fisher Scientific) for subsequent microscopic analysis using a Zeiss Axioscope A.1 (with AxioVision 4.8 software).

\section{Gene expression analysis}

Cartilage tissue, ectopically-formed on the tibia or fibrous periosteal tissue (on the tibia where none or little ectopic cartilage was formed), was harvested. Tissue samples where lysed in TRIzol (Life Technologies I Thermo Fisher Scientific, Carlsbad,

Table 1. Primer sequences for RT-qPCR. The 5' to 3' forward and reverse oligonucleotide sequences used for RT-qPCR are listed.

\begin{tabular}{|c|c|c|}
\hline oligo sets & Forward & Reverse \\
\hline Acan & CGGGACACCAACGAGACCTAT & CTGGCGACGTTGCGTAAAA \\
\hline Alp1 & GGAGGATGTGGCCGTCTTC & CTGCGTAAGCCATCACATGAG \\
\hline Col1a1 & CTGACTGGAAGAGCGGAGAGTAC & CCATGTCGCAGAAGACCTTGA \\
\hline Col2a1 & TGGGTGTTCTATTTATTTATTGTCTTCCT & GCGTTGGACTCACACCAGTTAGT \\
\hline col10a1 & AACCTGGACAACAGGGACTTACA & CCATATCCTGTTTCCCCTTTCTG \\
\hline Mmp13 & CGATGAAGACCCCAACCCTAA & ACTGGTAATGGCATCAAGGGATA \\
\hline PTHrP & AAGGGCAAGTCCATCCAAGA & CTCGGCGGTGTGTGGATTTC \\
\hline Sox 9 & AGTACCCGCACCTGCACAAC & CGCTTCTCGCTCTCGTTCAG \\
\hline Runx $\mathbf{2}$ & TGATGACACTGCCACCTCTGA & GCACCTGCCTGGCTCTTCT \\
\hline Vegfa & GTCAGAGAGCAACATCACCA & CATCTGCTGTGCTGTAGGAA \\
\hline $\mathbf{2 8 S}$ rRNA & GCCATGGTAATCCTGCTCAGTAC & GCTCCTCAGCCAAGCACATAC \\
\hline $\boldsymbol{\beta}$-Actin & GACAGGATGCAGAAGGAGATTACTG & CCACCGATCCACACAGAGTACTT \\
\hline GAPDH & ACTTTGTGAAGCTCATTTCCTGGTA & GTGGTTTGAGGGCTCTTACTCCTT \\
\hline
\end{tabular}


CA, USA). RNA isolation, RNA quantification by ultraviolet (UV) spectrometry (Biodrop; Isogen Life Sciences, Utrecht, the Netherlands) and cDNA synthesis were performed as described before (Caron et al., 2012a; Welting et al., 2011). Real time quantitative PCR (RT-qPCR) was performed using MESAGREEN qPCR MasterMix Plus for SYBR ${ }^{\circledR}$ Assay (Eurogentec, Seraing, Belgium). A CFX96 RealTime PCR Detection system (Biorad, Hercules, CA, USA) was used for amplification with the following protocol: initial denaturation $95{ }^{\circ} \mathrm{C}$ for $10 \mathrm{~min}$, followed by 40 cycles of amplification (denaturation $15 \mathrm{~s}$ at $95^{\circ} \mathrm{C}$ and annealing $1 \mathrm{~min}$ at $60^{\circ} \mathrm{C}$ ). Validated primer sequences used are listed in Table 1. Data were analysed using the $2^{-\Delta \Delta C t}$ method, mRNA expression was normalised to reference genes (28S rRNA, $\beta$-actin and GAPDH) and gene expression was calculated as fold change compared to control.

\section{Statistics}

Statistical analysis was performed using IBM SPSS 20.0 software (Chicago, IL, USA). Because of our group size, Mann Whitney $U$ test was applied for all measurements. Results with $p<0.05$ were regarded as significant. Data were presented as mean with standard error of the mean (SEM).

\section{Results}

Animal well-being and confirmation of COX-2 inhibition by reduced $\mathrm{PGE}_{2}$ levels

To determine the consequences of COX-2 inhibition on endochondral ossification, the skeletally-immature New Zealand white rabbits were systemically treated with celecoxib for $25 \mathrm{~d}$ (6 animals in control group and 6 animals in celecoxib group). Analysing blood plasma samples, we confirmed that celecoxib treatment efficiently inhibited in vivo $\mathrm{PGE}_{2}$ synthesis by $80 \%$ after $25 \mathrm{~d}$ and, thus, systemically inhibited COX-2 (Fig. 1A). Throughout the experiment, animal well-being and behaviour were observed daily. We did not observe any difference between the control and celecoxib-treated group. In addition, no significant differences were observed in the body weights during the entire experiment (Fig. 1B).

\section{Ulnar fracture healing and COX-2 inhibition}

To determine whether this systemic COX-2 inhibition influenced bone fracture healing, we employed a noncritical size defect model, which has been described before (Chai and Tang, 1986), to study fracture healing capacity.

To evaluate radiographical bone fracture healing in control and celecoxib-treated rabbits, plain radiographs were taken after $25 \mathrm{~d}$ of follow-up. Overall, these radiographs showed full bony bridging in all but one ulna in the control group. In the celecoxib-treated group only half of the ulnae showed full bony bridging, whereas the other half of the ulnae showed only partial bony bridging (Fig. 2A). Analysis by the Lane-Sandhu radiologic fracture scoring system, which measures bone formation, remodelling and union (Lane and Sandhu, 1987), revealed a significant difference in the average scores: $8.8(\mathrm{SEM} \pm 0.8)$ in the control group vs. 5.7 $(\mathrm{SEM} \pm 0.9)$ in the celecoxib-treated group (Fig. 2B). This indicated that fracture healing was indeed impaired in the celecoxib group.

To gain more insight in the newly-formed bone structure, bone fracture healing in the ulnae was analysed and evaluated by $\mu-C T$. Reconstructed 3D images confirmed the progression in fracture healing for both groups, as observed in the radiographs (Fig. 2C). $\mu-\mathrm{CT}$ data were analysed in greater detail by using a finite element model to predict

B

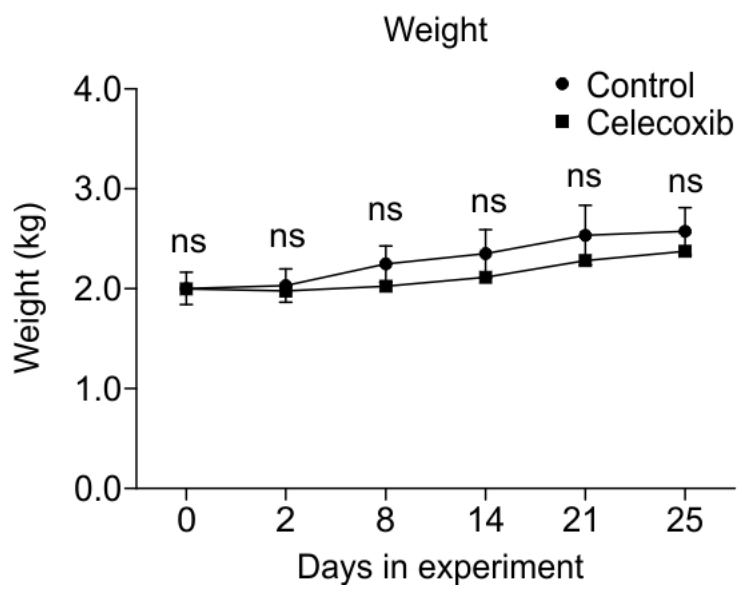

Fig. 1. Weight and systemic COX-2 inhibition during the experiment. (A) Systemic COX-2 inhibition was confirmed by measuring PGE ${ }_{2}$ levels in serum from pre-operative samples and in samples at day 25 ,

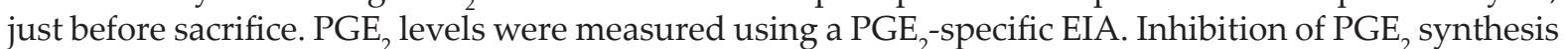
was determined as \% decrease as compared to pre-treatment serum samples. (B) Weight of the rabbits during the experiment in the control $(n=6)$ and celecoxib $(n=6)$ groups. Error bars indicate SEM, asterisk $\left.{ }^{*}\right)=p<0.05$, ns $=$ not significant. 
stiffness of the newly-formed bone (Fig. 2D). In both groups, one outlier was excluded from analysis due to a refracture of the sample, making the FEA unreliable. A significantly higher average compression stiffness was calculated for the control group as compared to the celecoxib-treated group [21082 N/mm $(\mathrm{SEM} \pm 1172 \mathrm{~N} / \mathrm{mm})$ vs. $14707 \mathrm{~N} /$ $\mathrm{mm}(\mathrm{SEM} \pm 3101 \mathrm{~N} / \mathrm{mm})$, respectively; $(p=0.048)]$. However, no significant differences were found in torsional stiffness [4416 Nmm/rad vs. 3477 Nmm/rad $(p=0.12)]$ and bending stiffness around the $\mathrm{X}$-axis [3839 N/mm vs. $2564 \mathrm{~N} / \mathrm{mm}(p=0.09)]$ or bending stiffness around the Y-axis [2288 N/mm vs. $1949 \mathrm{~N} /$

\section{A}

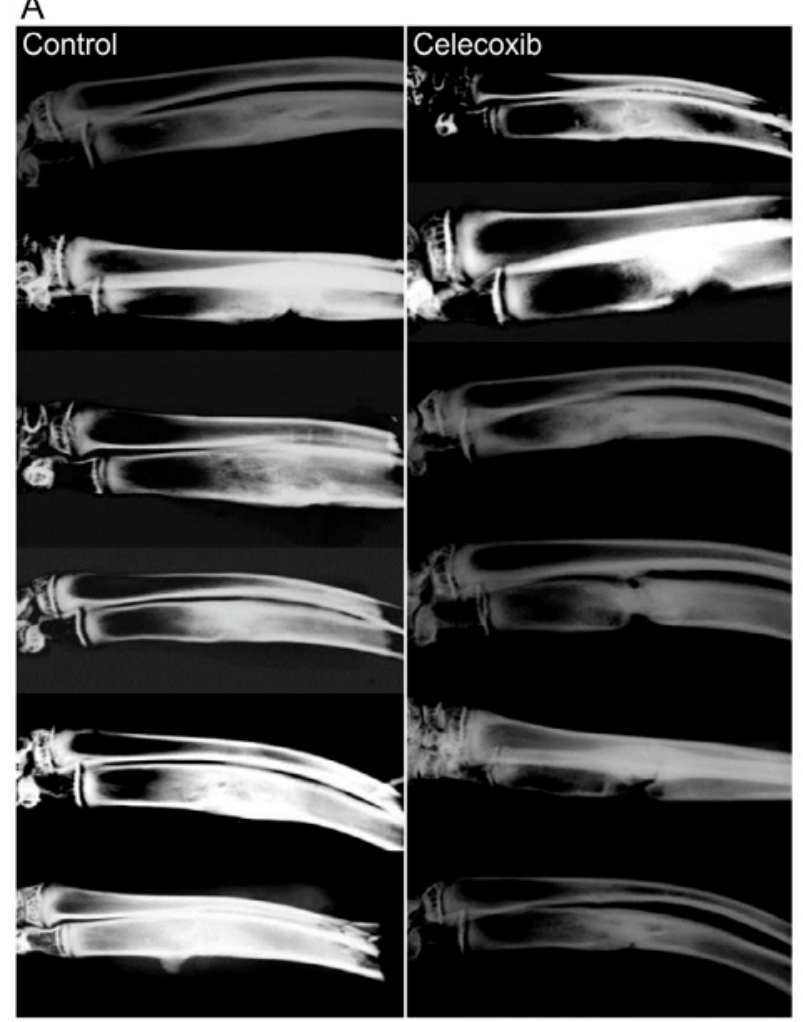

$\mathrm{mm}(p=0.13)$ ] (Fig. 2D). These data supported the observation of impaired fracture healing in the celecoxib-treated rabbits.

After $25 \mathrm{~d}$ of follow-up, von Kossa/thionine and Masson-Goldner trichrome stained histological samples showed, similar to radiographs and $\mu-\mathrm{CT}$ analyses, a delayed fracture healing in the celecoxibtreated rabbits (Fig. 3A-C). The control group showed bony bridging in all sections and reorganisation in most of the sections, only little callus tissue was still present and the cortices reorganised (Fig. 3A). In the celecoxib-treated group, full bony bridging was only observed in half of the sections. In the other half, more

B

\begin{tabular}{|c|c|c|c|}
\hline Lane-Sandhu & Control $(\boldsymbol{n}=\mathbf{6})$ & Celecoxib $(\boldsymbol{n}=\mathbf{6})$ & $\boldsymbol{p}$-value \\
\hline $\begin{array}{c}\text { Radiographic } \\
\text { score }\end{array}$ & $8.8( \pm 0.8)$ & $5.7( \pm 0.9)$ & $0.03^{*}$ \\
\hline
\end{tabular}

\section{C}
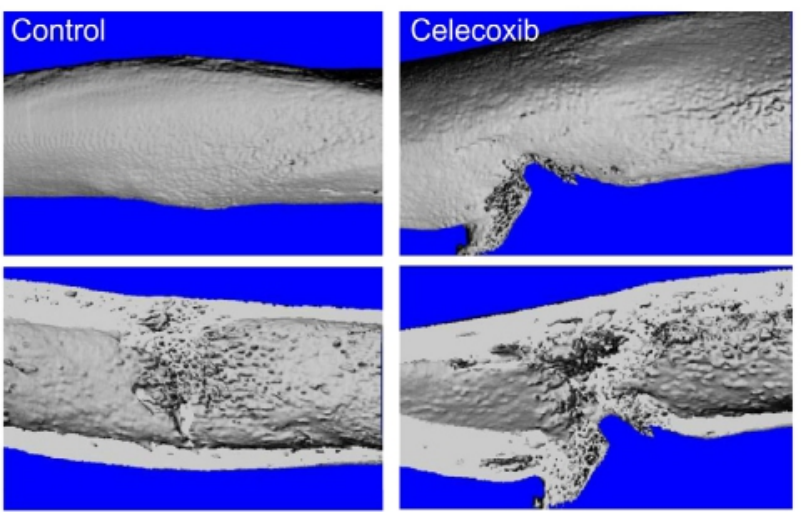

D

\begin{tabular}{|c|c|c|c|}
\hline FEA analysis & Control $(\boldsymbol{n}=\mathbf{6})$ & Celecoxib $(\boldsymbol{n}=6)$ & $\boldsymbol{p}$-value \\
\hline Compression stiffness $(\mathrm{N} / \mathrm{mm})$ & $21082( \pm 1172)$ & $14707( \pm 3101)$ & $0.048^{*}$ \\
\hline Torsional stiffness $(\mathrm{Nmm} / \mathrm{rad})$ & $4416( \pm 937)$ & $13477( \pm 577)$ & 0.12 \\
\hline Bending stiffness X- axis $(\mathrm{N} / \mathrm{mm})$ & $3839( \pm 580)$ & $2564( \pm 479)$ & 0.09 \\
\hline Bending stiffness Y- axis $(\mathrm{N} / \mathrm{mm})$ & $2288( \pm 396)$ & $1949( \pm 364)$ & 0.13 \\
\hline
\end{tabular}

Fig. 2. Impaired fracture healing in celecoxib-treated rabbits. Impaired fracture healing after celecoxib treatment in an experimental non-critical size defect model. A $5 \mathrm{~mm}$ defect was created in the distal ulna. After a follow-up of $25 \mathrm{~d}$, fracture healing was examined radiologically. (A) Full union in radiography of the ulna of the control group and only partial/delayed union in radiography of the ulna of the celecoxibtreated group. (B) In radiographs, bone union was assessed using the Lane-Sandhu scoring system. Significantly more union was measured in the control group, compared to the celecoxib treated group. (C) $3 \mathrm{D}$ reconstruction of $\mu$-CT images of the control group ulna and the celecoxib-treated ulna. Note the cortical bridging in the control group and a gap still present in the celecoxib-treated group. (D) Bone stiffness was assessed by finite element analysis. Either a significant difference or trend towards significance were observed among various parameters in control versus celecoxib-treated group. SEM is indicated between brackets. The * indicate significant $p$-values. 
callus tissue was still retained in the fracture region and less remodelling towards woven bone occurred (Fig. 3A). Furthermore, new bone formation and areas with retained cartilaginous tissue were still present in the fracture area of the celecoxib group whereas advanced reorganization towards woven bone was visible in the control group (Fig. 3B). In MasonGoldner trichrome stained sections, the celecoxib group showed more connective tissue in the fracture callus, whereas this was largely absent in the control group (Fig. 3C).

When fracture healing was quantified using an existing histological scoring system (Bos et al., 1983; Heiple et al., 1987), a significantly decreased score in the celecoxib-treated group was observed. The scoring system takes in account union, formation and remodelling of cartilaginous spongiosa, formation and remodelling of spongious bone, formation, remodelling and continuity of cortical bone (each side scored separately) and bone marrow formation. Each item can be scored from 0 to 4 , a total score of 24 means a fully-healed fracture and 0 means no healing occurred at all. A mean score of only $12.00(\mathrm{SEM} \pm 1.9)$ out of 24 was achieved in the celecoxib-treated group, whereas the control group achieved a mean score of $17.67(\mathrm{SEM} \pm 1.3)$ out of 24 . An overview of these results is shown in Fig. 3D. Overall, these data showed that systemic celecoxib treatment for $25 \mathrm{~d}$ in a non-critical size bone defect in skeletally-immature rabbits resulted in delayed endochondral bone fracture healing, as determined on plain radiographs, $\mu$-CT images and histology.

Growth plate development and COX-2 inhibition Systemic COX-2 inhibition delayed the bone fracture healing process in our non-critical size defect model, possibly by interfering with the endochondral ossification process. To determine whether COX-2 inhibition caused similar consequences in another scenario of endochondral ossification, we analysed growth plate development in the same rabbits. This had the additional benefit of analysing the effect of COX-2 inhibition on the EO process alone, without clouding of simultaneously occurring intramembranous ossification at the same site, as can be the case during fracture healing. In addition, the progenitor cell source for EO in the growth plate is different from in fracture healing: resting zone chondrocytes versus periosteal- and bone marrowderived mesenchymal cells, respectively.
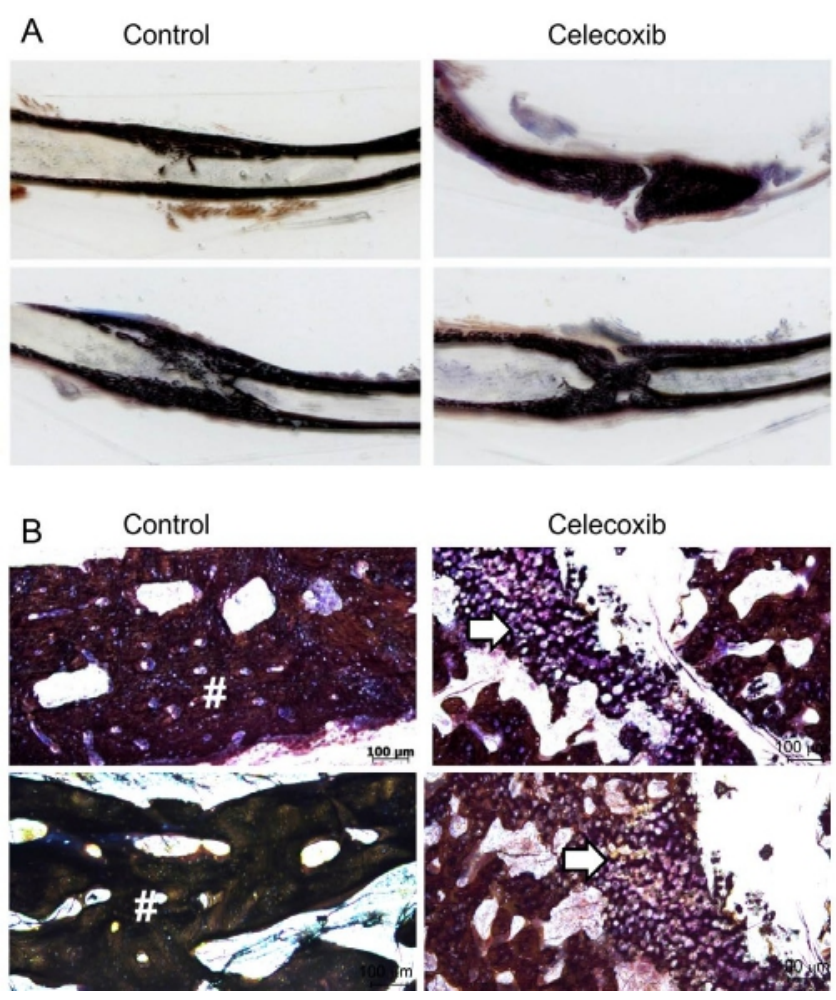

C
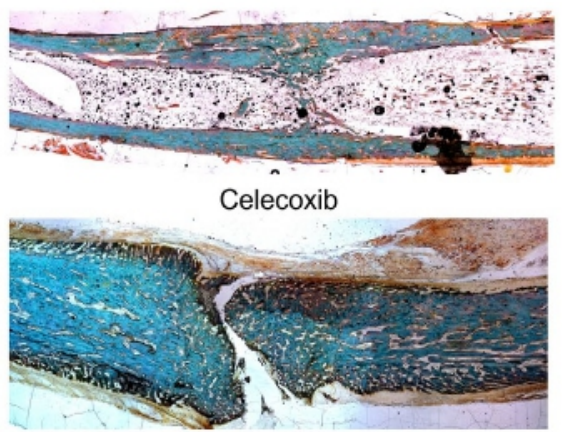

D
\begin{tabular}{|c|c|c|c|}
\hline Heiple score & Control $(\boldsymbol{n}=6)$ & Celecoxib $(\boldsymbol{n}=6)$ & $p$-value \\
\hline Union & $3.33( \pm 0.21)$ & $2.33( \pm 0.42)$ & 0.132 \\
\hline $\begin{array}{c}\text { Cartilaginous } \\
\text { spongiosa }\end{array}$ & $3.00( \pm 0.26)$ & $2.17( \pm 0.40)$ & 0.180 \\
\hline Spongious bona & $2.33( \pm 0.21)$ & $1.50( \pm 0.22)$ & 0.065 \\
\hline $\begin{array}{c}\text { Cortex } \\
\text { bridging_1 }\end{array}$ & $3.00( \pm 0.00)$ & $2.33( \pm 0.33)$ & 0.180 \\
\hline $\begin{array}{c}\text { Cortex } \\
\text { bridging_2 }\end{array}$ & $3.00( \pm 0.45)$ & $2.00( \pm 0.45)$ & 0.180 \\
\hline Bone marrow & $3.00( \pm 0.37)$ & $1.67( \pm 0.33)$ & $0.041^{*}$ \\
\hline Total & $17.67( \pm 1.28)$ & $12.00( \pm 1.53)$ & $\mathbf{0 . 0 4 1 ^ { * }}$ \\
\hline
\end{tabular}

Fig. 3. Impaired histological fracture healing in celecoxib-treated rabbits. Delayed fracture healing as seen in histologic sections of the same specimens. (A) An overview of vonKossa/thionine and Masson-Goldner trichrome stained sections showed bony bridging of the cortex in the control group, but in the celecoxibtreated group a clear gap was still visible in the region where the defect was created. (B) A magnification of the vonKossa/thionine stained section shown in $\mathbf{A}$ (scale bars represent $100 \mu \mathrm{m})$ showed advanced reorganisation towards woven bone (\#) in the control group, whereas more cartilaginous tissue (white arrow) was still present and only little reorganisation had occurred in the celecoxib-treated rabbits. (C) Masson-Goldner trichrome staining. (D) Fracture healing was significantly impaired in the celecoxibtreated rabbits, when histologically analysed by a modified version of Heiple's histologic scoring system. SEM is depicted between brackets. The ${ }^{*}$ indicate significant $p$-values. 
A

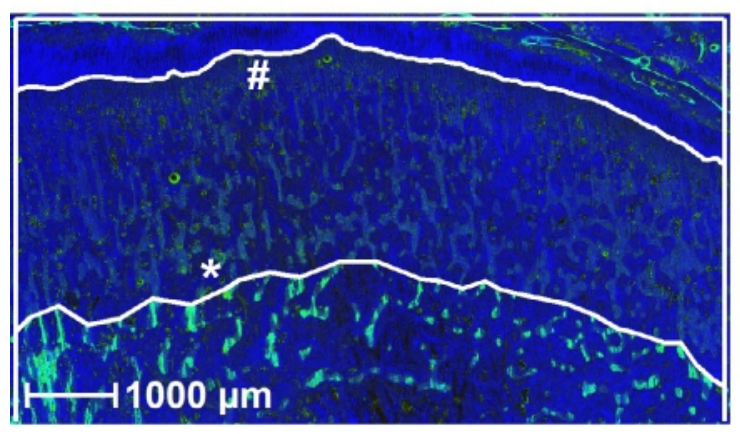

Celecoxib

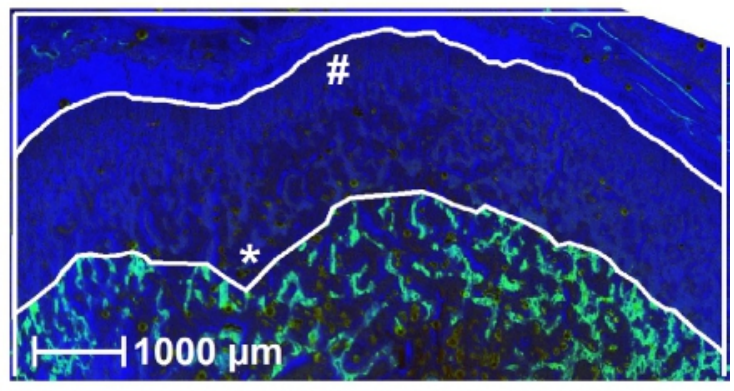

B

\begin{tabular}{|c|c|c|c|}
\hline & Control $(\boldsymbol{n}=6)$ & Celecoxib $(\boldsymbol{n}=6)$ & $\boldsymbol{p}$-value \\
\hline $\begin{array}{c}\text { Advancement of } \\
\text { minaralisation front }\end{array}$ & $2436( \pm 142) \mu \mathrm{m}$ & $1830( \pm 54) \mu \mathrm{m}$ & $0.0043^{*}$ \\
\hline
\end{tabular}

\section{C}
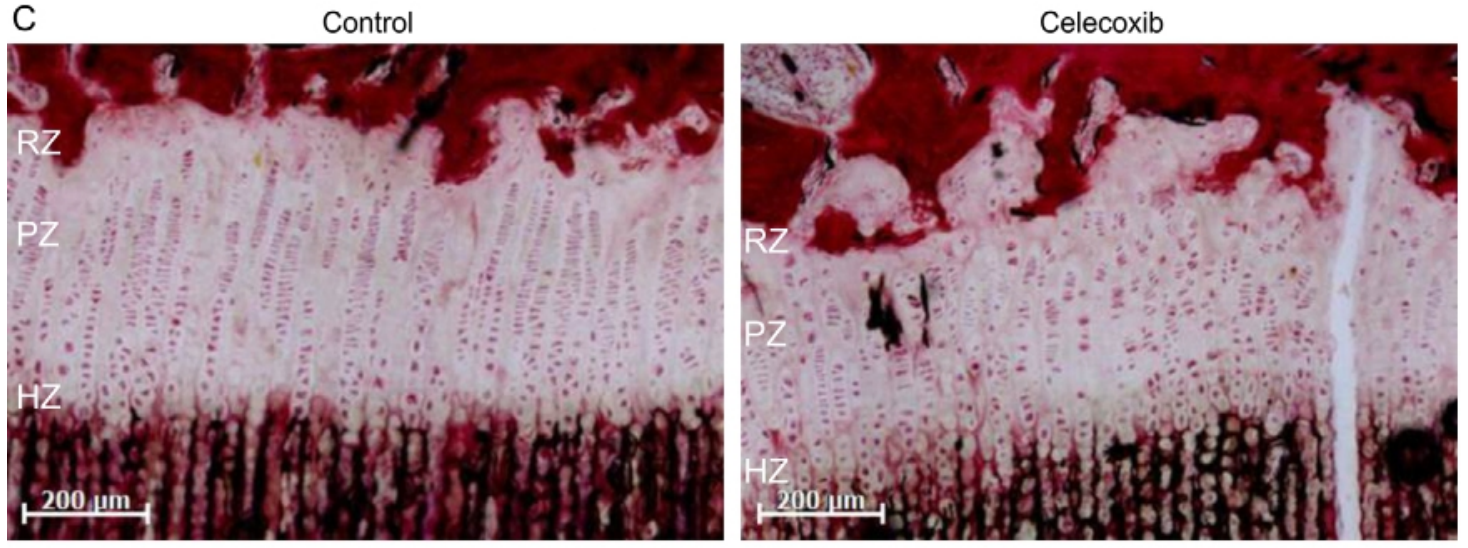

D

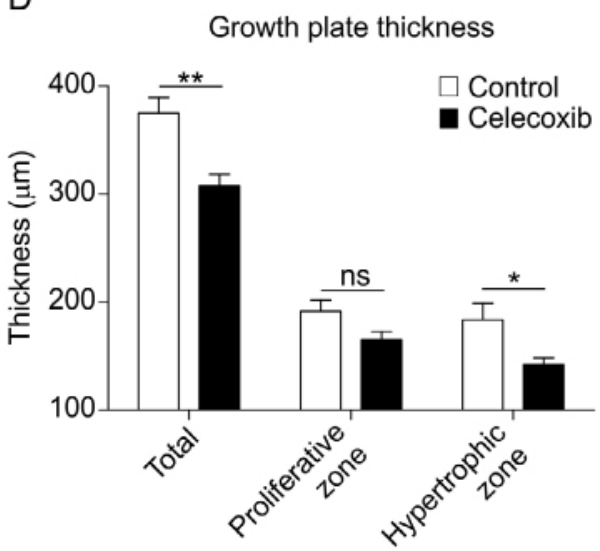

Fig. 4. Celecoxib inhibited advancement of the mineralisation front. The distal femoral growth plate was examined histologically. (A) The calcein green mineralisation front $\left(^{*}\right)$ at day 14 was visualised and compared to the transition between proliferative zone and hypertrophic zone of the growth plate (\#) at day 25. The surface of the growth plates was measured over a standard width of $8 \mathrm{~mm}$ and the average growth was calculated. The scale bars represent $1000 \mu \mathrm{m}$. (B) Significantly more advancement of the mineralisation front was observed in the control group compared to celecoxib-treated group. (C) In adjacent sections stained with H\&E, average thickness was calculated for the total growth plate, the proliferative zone (PZ) and the hypertrophic zone (HZ). In addition, normal columnar chondrocytes could be seen in the control group growth plate and a less organised structure of the chondrocytes and a less marked transition between resting zone area (RZ) and proliferative zone was seen in the celecoxib treated rabbits. (D) A significant decrease in thickness of the total growth plate and in the hypertrophic zone was observed, but no significant difference was present in the proliferative zone. Standard error of the mean is depicted between brackets. The ${ }^{*}$ indicate significant $p$-values $(p<0.05),{ }^{* *}=p<0.01, \mathrm{~ns}=$ not significant. 
To follow new bone formation originating from endochondral ossification in the growth plate, fluorescent calcium labelling was applied by calcein green injection at day 14 (11 d prior to sacrifice) and analysed in histological sections of the growth plate. Calcium labelling by fluorochromes, as calcein green, allows to determine the location of active mineralisation at a given time point (time of injection) (van Gaalen et al., 2010). The injection of calcein green at day 14 caused a clearly visible green fluorescent front at the diaphyseal side of the growth plate of the rabbits' distal femora (mineralisation front) (Fig. $4 \mathrm{~A})$. In the same sections, the transition between proliferative zone and hypertrophic zone of the growth plate could also be observed. The distance between the fluorescent mineralisation front and the proliferative/hypertrophic transition zone was indicative of the growth that occurred between
A

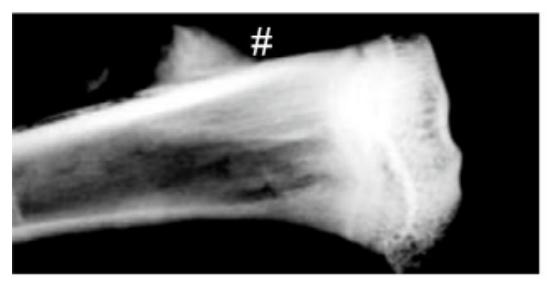

C

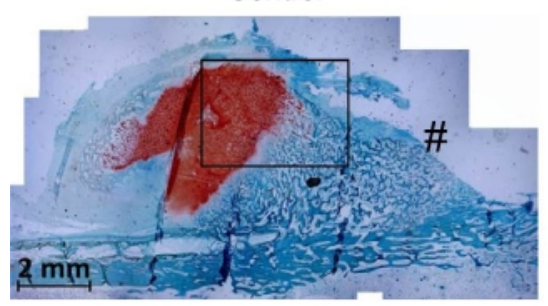

D
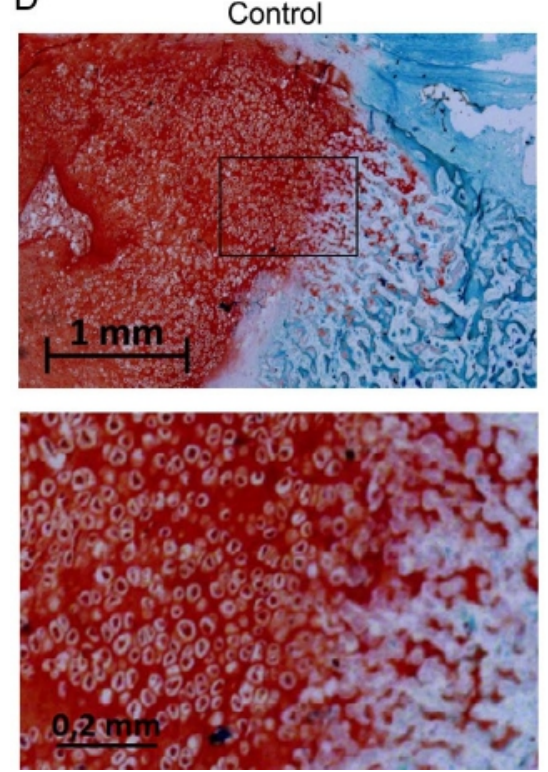

Celecoxib

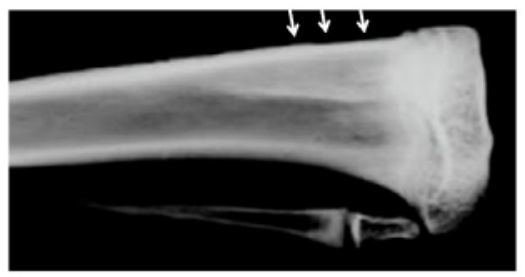

Celecoxib
B

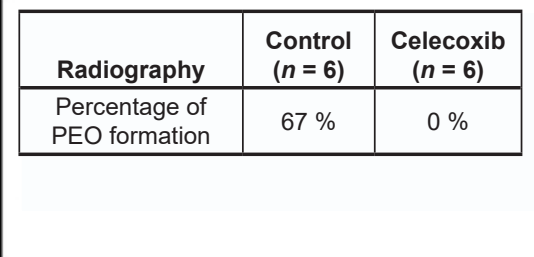

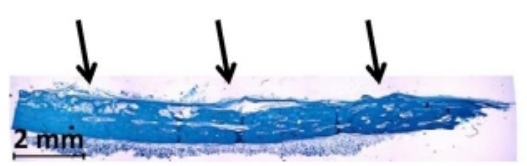

E

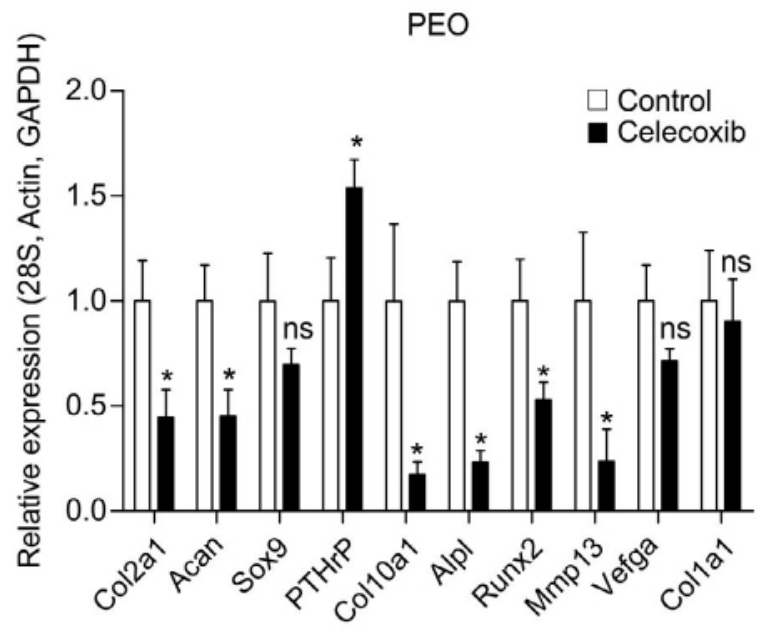

Fig. 5. Impaired PEO formation in celecoxib-treated rabbits. A periosteal endochondral model was used to examine the influence of celecoxib on chondrogenesis. An agarose gel was injected between periosteum and bone of the upper tibia to induce PEO. (A) Plain radiographs showed (the mineralised part of) PEO (\#) in control and celecoxib-treated rabbits (white arrows point to the location of injection). (B) In $67 \%$ of the injected control rabbits and in none of the celecoxib-treated rabbits PEO formation was observed. (C) Safranin O/fast green-stained histological section of the same specimen illustrating cartilage formation and mineralisation (\#) in control group and in the celecoxib-treated rabbits, with no clear PEO formed (black arrows point to the location of injection). This showed that not only mineralisation was inhibited, but the lack of cartilaginous PEO formation indicated an inhibited chondrogenic differentiation. (D) Higher magnification of panel C: the transition of cartilage into the ossified part is visible in more detail. (E) Gene expression analysis of indicated genes was performed by RT-qPCR on PEO tissue in control and celecoxib-treated rabbits. Data are presented as relative expression compared to control condition and normalised to a housekeeping index consisting of $28 \mathrm{~S}$ rRNA, $\beta$-actin and GAPDH. Bars represent mean \pm SEM. ${ }^{*}=p<0.05, \mathrm{~ns}=$ not significant. 
incorporation of calcein green and sacrifice. The growth for the control group was $2436 \mu \mathrm{m}( \pm 142 \mu \mathrm{m})$ and for the celecoxib-treated group $1830 \mu \mathrm{m}( \pm 54 \mu \mathrm{m})$, which was a significantly shorter distance (Fig. 4B). This showed that celecoxib treatment also inhibited endochondral ossification during the growth plate development.

In sequential sections stained with H\&E (Fig. 4C), we further focused on the growth plates of these long bones, to determine whether the inhibition of advancement of the epiphyseal mineralisation front originated from the growth plate (and, thus, the chondrogenic phase of endochondral ossification). The total thickness of the growth plates in the control rabbits was $375.1 \mu \mathrm{m}( \pm 14.2 \mu \mathrm{m})$, whereas the total thickness of the growth plates in the celecoxib-treated rabbits was only $307.9 \mu \mathrm{m}( \pm 10.34 \mu \mathrm{m})(p<0.05)$. Also, and in concert with our previous work (Welting et al., 2011), the thickness of the hypertrophic zone was significantly decreased in the celecoxib-treated group (Fig. 4D). Collectively, these results showed that growth plate development was inhibited and, since growth plate development was driven by chondrogenic differentiation, it was likely that at least a part of the reduced growth plate development caused by celecoxib, could be explained by an impaired chondrogenic differentiation.

\section{PEO and COX-2 inhibition}

PEO can be used as a model for studying in vivo endochondral bone formation because, similarly to the growth plate, it sequentially completes the stages of chondrogenic differentiation during endochondral ossification (Emans et al., 2007). Different from the growth plate, PEO formation allowed for the specific analysis of the effect of COX-2 inhibition on the newly-formed endochondral ossification processes (as celecoxib treatment started almost simultaneously with induction of PEO) and, thus, study early phases of chondrogenic differentiation during EO. To study whether celecoxib not only had an influence on osteogenic differentiation, but also on chondrogenic differentiation, we implemented this method for ectopically inducing endochondral ossification in the same rabbits used for the noncritical size defect procedure. We analysed whether celecoxib treatment was able to alter PEO formation, as a model for chondrogenic differentiation, through radiography, histology and gene expression analysis. Radiography and histology showed a distinctive $67 \%$ PEO formation (4 out of 6 injection sites) in the control group and a $0 \%$ distinctive PEO formation (0 of 6 injections sites) in the celecoxib-treated group (Fig. 5A,B). Safranin O staining, to detect proteoglycans, indicative of cartilage formation (Fig. 5C,D), showed that rabbits in the celecoxib-treated group did not detectably develop cartilage tissue in the PEO tissue. In Fig. 5C the tibial cortex and fibrous periosteal tissue could be seen in the celecoxib group, but no PEO tissue was developed. In the control group, cartilaginous tissue was formed, which, at the time of harvest, was gradually ossifying. This could be seen in more detail in Fig. 5D. Gene expression analysis of the PEO tissue or fibrous periosteal tissue at the site of agarose injection showed that celecoxib significantly impaired the expression of collagen type II (Col2a1), aggrecan (Acan), collagen type X (Col10a1), alkaline phosphatase (Alpl), Runt-related transcription factor 2 (Runx2) and matrix metalloproteinase 13 (Mmp13). Expression of parathyroid hormone-related peptide (PTHrP) was upregulated. No significant differences were found in the expression of SRY box 9 (Sox9), vascular endothelial growth factor alpha (Vegfa) or collagen type I (Col1a1) (Fig. 5E). Overall, these data indicated that systemic inhibition of COX-2 by celecoxib impaired the formation of PEO tissues, suggesting that, in this model, systemic COX-2 inhibition had a negative effect on the initiation of the chondrogenic phase of endochondral ossification.

\section{Discussion}

We showed that the inhibition of COX-2 by celecoxib influenced the chondrogenic phase of endochondral ossification in vivo, affecting not only fracture healing, but also growth plate development and ectopic periosteal cartilage formation.

Fracture healing by EO in a non-critical size defect in the ulna was found to be delayed on radiographs, $\mu$-CT images and histology in the celecoxib-treated animals, which is consistent with previous reports, where COX-2 is selectively inhibited (Gerstenfeld et al., 2003c; Goodman et al., 2002; Herbenick et al., 2008; Simon et al., 2002; Simon and O'Connor, 2007). Remarkably, the non-fused fractures in the celecoxibtreated animals were characterised by the presence of retained cartilaginous tissue, which was likely indicative of delayed EO. Impaired bone healing was confirmed by FEA, in which a significant difference in compression strength was observed. Compression strength was the only parameter that differed significantly between control and celecoxib-treated groups. Compression strength largely depends on cortical integrity (Fyhrie and Vashishth, 2000) and, since the celecoxib-treated animals specifically presented lower FEA compression strength, it was likely that the mode of impaired fracture healing due to celecoxib treatment involved impaired cortical healing as a result of delayed endochondral ossification. Indeed, this was confirmed by our histological examinations.

Using a calcium-binding fluorochrome, we were able to demonstrate that the mineralisation front in the growth plate advanced less over time in the celecoxibtreated animals compared to control. This implicated an impaired advancement of endochondral-driven bone growth and confirmed our previous findings (Welting et al., 2011). In the celecoxib-treated rabbits, the growth plates were significantly shorter, which can be mainly attributed to a shorter hypertrophic zone. This shorter hypertrophic zone can be caused 
by an impaired progression into hypertrophy (Welting et al., 2011). Our data strongly indicated that - apart from the possibility that osteogenic remodelling in already developed bones might be affected by celecoxib treatment - the chondrogenic phase of endochondral ossification was sensitive to the celecoxib treatment.

In addition to EO in fracture healing and growth plate development, the same animals were used to examine the chondrogenic phase of endochondral ossification, according to a previously described model for in vivo ectopic cartilage formation (Emans et al., 2007). We found that no distinctive ectopic cartilage tissue was formed in the celecoxib-treated group. Ectopic periosteal cartilage formation and the formation of cartilaginous fracture callus are de novo initiated cellular processes, requiring an initial inflammatory environment (Caron et al., 2012b; Gerstenfeld et al., 2003a; Gerstenfeld et al., 2003b). With the systemic celecoxib-dependent reduction of COX-2 activity, an essential inflammatory reaction may be dampened, resulting in an impaired initiation of chondrogenic differentiation or inflammationdriven osteogenic remodelling of fracture callus. A challenge is to define at which stage of EO COX-2 is involved and to clarify why EO seemed to be delayed in fracture healing and growth plate development, while being inhibited in the PEO model. EO can be divided into 4 stages: 1 ) initiation of chondrogenic differentiation of chondroprogenitor cells, 2) chondrocyte proliferation, 3) hypertrophic differentiation, 4) vascularisation and apoptosis (Caron et al., 2012b; Caron et al., 2014). Previous work from our group shows a bi-phasic COX-2 expression pattern during chondrogenic differentiation in vitro (Caron et al., 2016; Welting et al., 2011). The two stages, corresponding to COX-2 expression peaks, resemble early differentiation and chondrocyte hypertrophy. This suggests that inhibition of COX-2 could have an influence on both early chondrogenic differentiation, as well as, late chondrogenic differentiation. Therefore, inhibition of COX-2 could influence both the initiation of chondrogenic differentiation and chondrocyte hypertrophy. According to the present study, growth plate development was an already ongoing process and fracture healing and ectopic periosteal chondrogenic differentiation were initiated simultaneously to COX-2 inhibition. During fracture healing and ectopic periosteal chondrogenic differentiation, the first peak of the bi-phasic COX2 expression was likely inhibited, whereas, in growth plate development, COX-2 inhibition might interfere with the already ongoing chondrogenic differentiation. Therefore, we speculated that it was the inhibition of this biphasic COX-2 expression that was likely to cause differential effects on fracture healing, growth plate development and ectopic periosteal chondrogenic differentiation.

The skeletal mechanism of action of arachidonic acid-derived eicosanoids remains a topic of investigation (O'Connor and Lysz, 2008). For instance, the prostanoid receptors of PGE2 (EP-1, EP4) have different roles in chondrocyte and osteocyte differentiation and, therefore, in fracture healing. EP-1-/- mice have enhanced osteoblast differentiation and accelerated fracture repair (Zhang et al., 2011), whereas EP-2 and EP-4 agonists improve fracture healing (Paralkar et al., 2003). However, in COX-2 -/- mice, fracture healing is severely impaired, but these mice have no reported skeletal abnormalities (Simon et al., 2002). The latter is inconsistent with our findings, as we observed an effect of celecoxib on the maturation of the growth plate, implicating that COX2 played a role during endochondral ossification. Finally, in a rat model, reduction of leukotriene synthesis by inhibition of 5-lipoxygenase accelerates fracture healing by increasing COX-2 expression in fracture callus and progression into hypertrophy to complete endochondral ossification (Cottrell and O'Connor, 2009; Manigrasso and O'Connor, 2010).

COX-2 is a rate-limiting enzyme in the turnover of arachidonic acid to prostaglandins (Ledwith et al., 1997). The decreased levels of PGE2 in the rabbit blood plasma at day 25 confirmed that we were able to inhibit COX-2 activity systemically in vivo. In our experiment, we have chosen to use a celecoxib dose equivalent to $800 \mathrm{mg} / \mathrm{d}$ in humans. This is a high dose to be used in orthopaedic conditions and rheumatic diseases, but non-toxic and described as safe for use in a gastrointestinal toxicity study (Silverstein et al., 2000). It is unknown whether the effects of celecoxib, which we reported, would have also been observed if lower concentrations would have been used or with other NSAIDs. Furthermore, local instead of systemic administration of celecoxib might differently influence the course of chondrogenic differentiation, but this will be topic of further studies.

Our study design had a limitation, but at the same time an opportunity. Using a single animal for multiple experimental models could be a confounding factor, as we had no control on factors that might influence each other. This could be addressed by using separate animals for each study design. However, considering inter-animal variation when using different animals for different models, we would never have been able to make the comparison as accurate as we did using this combined model. Moreover, the potential influence of one factor on the other would be expected to be similar in each rabbit. The only difference between the two groups was the administration of celecoxib, which was the variable we aimed to test.

\section{Conclusions}

We confirmed previous findings according to which selective COX-2 inhibition (by celecoxib) causes impaired fracture healing (Simon et al., 2002) and, more importantly, we showed that chondrogenic differentiation during EO was impaired by COX-2 
inhibition. This impaired chondrogenic differentiation had an impact on the development of the fracture callus, growth plate development and ectopic cartilage formation. The impaired fracture healing was probably at least partially a result of the effects of celecoxib on the chondrogenic phase of EO, similarly to results found for growth plate development and, therefore, not solely a consequence of impaired osteogenesis. This chondrogenic involvement may have other, yet unknown, implications for the use of COX-2 inhibitors in pregnant women, children and patients suffering from a fracture and necessitates further clinical investigation.

\section{Acknowledgments}

This work was financially supported by the Annafonds INOREF (grant 08/42 to TW) and the Dutch Arthritis Association (LLP14). The authors would like to thank L. Peeters (Department of Orthopaedic Surgery, MUMC, the Netherlands) for performing the gene expression analysis.

\section{References}

Bos GD, Goldberg VM, Powell AE, Heiple KG, Zika JM (1983) The effect of histocompatibility matching on canine frozen bone allografts. J Bone Joint Surg Am 65: 89-96.

Bouwmeester SJ, Beckers JM, Kuijer R, van der Linden AJ, Bulstra SK (1997) Long-term results of rib perichondrial grafts for repair of cartilage defects in the human knee. Int Orthop 21: 313-317.

Brooks P, Emery P, Evans JF, Fenner H, Hawkey CJ, Patrono C, Smolen J, Breedveld F, Day R, Dougados M, Ehrich EW, Gijon-Banos J, Kvien TK, Van Rijswijk MH, Warner T, Zeidler H (1999) Interpreting the clinical significance of the differential inhibition of cyclooxygenase- 1 and cyclooxygenase- 2 . Rheumatology (Oxford) 38: 779-788.

Brown WE, Potter HG, Marx RG, Wickiewicz TL, Warren RF (2004) Magnetic resonance imaging appearance of cartilage repair in the knee. Clin Orthop Relat Res 422: 214-223. PMID: 15187860.

Bulstra SK, Drukker J, Kuijer R, Buurman WA, van der Linden AJ (1993) Thionine staining of paraffin and plastic embedded sections of cartilage. Biotech Histochem 68: 20-28.

Caldwell KL, Wang J (2014) Cell-based articular cartilage repair: the link between development and regeneration. Osteoarthritis Cartilage 23: 351-362.

Calori GM, Albisetti W, Agus A, Iori S, Tagliabue L (2007) Risk factors contributing to fracture nonunions. Injury 38 Suppl 2: S11-18.

Caron MM, Emans PJ, Coolsen MM, Voss L, Surtel DA, Cremers A, van Rhijn LW, Welting TJ (2012a) Redifferentiation of dedifferentiated human articular chondrocytes: comparison of 2D and 3D cultures. Osteoarthritis Cartilage 20: 1170-1178.

Caron MM, Emans PJ, Sanen K, Surtel DA, Cremers A, Ophelders D, van Rhijn LW, Welting TJ (2016) The role of prostaglandins and COX-enzymes in chondrogenic differentiation of ATDC5 progenitor cells. PloS One 11: e0153162.

Caron MM, Emans PJ, Surtel DA, Cremers A, Voncken JW, Welting TJ, van Rhijn LW (2012b) Activation of NF-kappaB/p65 facilitates early chondrogenic differentiation during endochondral ossification. PloS One 7: e33467.

Caron MM, Welting TJ, van Rhijn LW, Emans PJ (2014)Targetting inflammatory processes for optimization of cartilage homeostasis and tissue repair techniques. In: ICRS: Developing insights in cartilage repair (Peterson L, Emans PJ, eds), SpringerVerlag London, pp 43-63.

Chai BF, Tang XM (1986) Ultrastructural investigation of experimental fracture healing. Role of osteogenesis played by fibroblasts. Chin Med J (Engl) 99: 126-132.

Cottrell JA, O'Connor JP (2009) Pharmacological inhibition of 5-lipoxygenase accelerates and enhances fracture-healing. J Bone Joint Surg Am 91: 2653-2665.

Dickhut A, Pelttari K, Janicki P, Wagner W, Eckstein V, Egermann M, Richter W (2009) Calcification or dedifferentiation: requirement to lock mesenchymal stem cells in a desired differentiation stage. J Cell Physiol 219: 219-226.

Emans PJ, Caron MM, van Rhijn LW, Welting TJ (2012)Endochondral bone formation as blueprint for regenerative medicine. In: Tissue regeneration - from basic biology to clinical application (Davies PJ, ed), InTech, pp 399-424.

Emans PJ, Hulsbosch M, Wetzels GM, Bulstra SK, Kuijer R (2005) Repair of osteochondral defects in rabbits with ectopically produced cartilage. Tissue Eng Part C Methods 11: 1789-1796.

Emans PJ, Spaapen F, Surtel DA, Reilly KM, Cremers A, van Rhijn LW, Bulstra SK, Voncken JW, Kuijer R (2007) A novel in vivo model to study endochondral bone formation; HIF-1alpha activation and BMP expression. Bone 40: 409-418.

Emans PJ, van Rhijn LW, Welting TJ, Cremers A, Wijnands N, Spaapen F, Voncken JW, Shastri VP (2010) Autologous engineering of cartilage. Proc Natl Acad Sci U S A 107: 3418-3423.

Frame JW (1980) A convenient animal model for testing bone substitute materials. J Oral Surg 38: 176180.

Fyhrie DP, Vashishth D (2000) Bone stiffness predicts strength similarly for human vertebral cancellous bone in compression and for cortical bone in tension. Bone 26: 169-173.

Gerner P, O'Connor JP (2008) Impact of analgesia on bone fracture healing. Anesthesiology 108: 349350 .

Gerstenfeld LC, Cho TJ, Kon T, Aizawa T, Tsay A, Fitch J, Barnes GL, Graves DT, Einhorn TA (2003a) Impaired fracture healing in the absence 
of TNF-alpha signaling: the role of TNF-alpha in endochondral cartilage resorption. J Bone Miner Res 18: 1584-1592.

Gerstenfeld LC, Cullinane DM, Barnes GL, Graves DT, Einhorn TA (2003b) Fracture healing as a postnatal developmental process: molecular, spatial, and temporal aspects of its regulation. J Cell Biochem 88: 873-884.

Gerstenfeld LC, Thiede M, Seibert K, Mielke C, Phippard D, Svagr B, Cullinane D, Einhorn TA (2003c) Differential inhibition of fracture healing by non-selective and cyclooxygenase- 2 selective nonsteroidal anti-inflammatory drugs. J Orthop Res 21: 670-675.

Geusens P, Emans PJ, de Jong JJ, van den Bergh J (2013) NSAIDs and fracture healing. Curr Opin Rheumatol 25: 524-531.

Goodman S, Ma T, Trindade M, Ikenoue T, Matsuura I, Wong N, Fox N, Genovese M, Regula D, Smith RL (2002) COX-2 selective NSAID decreases bone ingrowth in vivo. J Orthop Res 20: 1164-1169.

Hadjiargyrou M, O'Keefe RJ (2014) The convergence of fracture repair and stem cells: interplay of genes, aging, environmental factors and disease. J Bone Miner Res 29: 2307-2322.

Heiple KG, Goldberg VM, Powell AE, Bos GD, Zika JM (1987) Biology of cancellous bone grafts. Orthop Clin North Am 18: 179-185.

Herbenick MA, Sprott D, Stills H, Lawless M (2008) Effects of a cyclooxygenase 2 inhibitor on fracture healing in a rat model. Am J Orthop 37: E133137.

Isaksson H, Grongroft I, Wilson W, van Donkelaar CC, van Rietbergen B, Tami A, Huiskes R, Ito K (2009) Remodeling of fracture callus in mice is consistent with mechanical loading and bone remodeling theory. J Orthop Res 27: 664-672.

Kronenberg HM (2003) Developmental regulation of the growth plate. Nature 423: 332-336.

Lane JM, Sandhu HS (1987) Current approaches to experimental bone grafting. Orthop Clin North Am 18: 213-225.

Lau KH, Kothari V, Das A, Zhang XB, Baylink DJ (2013) Cellular and molecular mechanisms of accelerated fracture healing by COX2 gene therapy: studies in a mouse model of multiple fractures. Bone 53: 369-381.

Ledwith BJ, Pauley CJ, Wagner LK, RokosCL, Alberts DW, Manam S (1997) Induction of cyclooxygenase-2 expression by peroxisome proliferators and nontetradecanoylphorbol 12,13-myristate-type tumor promoters in immortalized mouse liver cells. J Biol Chem 272: 3707-3714.

Mackie EJ, Ahmed YA, Tatarczuch L, Chen KS, Mirams M (2008) Endochondral ossification: how cartilage is converted into bone in the developing skeleton. Int J Biochem Cell Biol 40: 46-62.

Manigrasso MB, O'Connor JP (2010) Accelerated fracture healing in mice lacking the 5-lipoxygenase gene. Acta Orthop 81: 748-755.
Marsell R, Einhorn TA (2011) The biology of fracture healing. Injury 42: 551-555.

Matos MA, Araujo FP, Paixao FB (2008) Histomorphometric evaluation of bone healing in rabbit fibular osteotomy model without fixation. J Orthop Surg Res 3: 4.

O'Connor JP, Lysz T (2008) Celecoxib, NSAIDs and the skeleton. Drugs of today 44: 693-709.

Paralkar VM, Borovecki F, Ke HZ, Cameron KO, Lefker B, Grasser WA, Owen TA, Li M, DaSilvaJardine P, Zhou M, Dunn RL, Dumont F, Korsmeyer R, Krasney P, Brown TA, Plowchalk D, Vukicevic S, Thompson DD (2003) An EP2 receptor-selective prostaglandin E2 agonist induces bone healing. Proc Natl Acad Sci U S A 100: 6736-6740.

Park J, Gebhardt M, GolovchenkoS, Perez-Branguli F, Hattori T, Hartmann C, Zhou X, deCrombrugghe B, Stock M, Schneider H, von der Mark K (2015) Dual pathways to endochondral osteoblasts: a novel chondrocyte-derived osteoprogenitor cell identified in hypertrophic cartilage. Biol Open 4: 608-621.

Sachs L (2004) Angewandte statistik: anwendung statistischer methoden. Springer. DOI: 10.1007/9783-662-05750-6.

Santolini E, West R, Giannoudis PV (2015) Risk factors for long bone fracture non-union: a stratification approach based on the level of the existing scientific evidence. Injury 46 Suppl 8: S8-S19.

Shefelbine SJ, Simon U, Claes L, Gold A, Gabet Y, Bab I, Muller R, Augat P (2005) Prediction of fracture callus mechanical properties using $\mu-\mathrm{CT}$ images and voxel-based finite element analysis. Bone 36: 480-488.

Silverstein FE, Faich G, Goldstein JL, Simon LS, Pincus T, Whelton A, Makuch R, Eisen G, Agrawal NM, Stenson WF, Burr AM, Zhao WW, Kent JD, Lefkowith JB, Verburg KM, Geis GS (2000) Gastrointestinal toxicity with celecoxib vs. nonsteroidal anti-inflammatory drugs for osteoarthritis and rheumatoid arthritis: the CLASS study: a randomized controlled trial. Celecoxib longterm arthritis safety study. JAMA 284: 1247-1255.

Simon AM, Manigrasso MB, O'Connor JP (2002) Cyclo-oxygenase 2 function is essential for bone fracture healing. J Bone Miner Res 17: 963-976.

Simon AM, O'Connor JP (2007) Dose and timedependent effects of cyclooxygenase-2 inhibition on fracture-healing. J Bone Joint Surg Am 89: 500-511.

Spinarelli A, Patella V, Petrera M, Abate A, Pesce V, Patella S (2011) Heterotopic ossification after total hip arthroplasty: our experience. Musculoskelet Surg 95: 1-5.

Thompson Z, Miclau T, Hu D, Helms JA (2002) A model for intramembranous ossification during fracture healing. J Orthop Res 20: 1091-1098.

van Gaalen SM, Kruyt MC, Geuze RE, de Bruijn JD, Alblas J, Dhert WJ (2010) Use of fluorochrome labels in in vivo bone tissue engineering research. Tissue Eng Part B Rev 16: 209-217.

van Osch GJ, Brittberg M, Dennis JE, BastiaansenJenniskens YM, Erben RG, Konttinen YT, Luyten FP 
(2009) Cartilage repair: past and future-lessons for regenerative medicine. J Cell Mol Med 13: 792-810.

van Rietbergen B, Majumdar S, Pistoia W, Newitt DC, Kothari M, Laib A, Ruegsegger P (1998) Assessment of cancellous bone mechanical properties from micro-FE models based on $\mu$-CT, pQCT and MR images. Technol Health Care 6: 413-420.

Welting TJ, Caron MM, Emans PJ, Janssen MP, Sanen K, Coolsen MM, Voss L, Surtel DA, Cremers A, Voncken JW, van Rhijn LW (2011) Inhibition of cyclooxygenase-2 impacts chondrocyte hypertrophic differentiation during endochondral ossification. Eur Cell Mater 22: 420-437.

Yang G, Zhu L, Hou N, Lan Y, Wu XM, Zhou B, Teng Y, Yang X (2014) Osteogenic fate of hypertrophic chondrocytes. Cell Res 24: 1266-1269.

Zhang M, Ho HC, Sheu TJ, Breyer MD, Flick LM, Jonason JH, Awad HA, Schwarz EM, O'Keefe RJ (2011) EP1(-/-) mice have enhanced osteoblast differentiation and accelerated fracture repair. J Bone Miner Res 26: 792-802.

Zhou X, von der Mark K, Henry S, Norton W, Adams H, de Crombrugghe B (2014) Chondrocytes transdifferentiate into osteoblasts in endochondral bone during development, postnatal growth and fracture healing in mice. PLoS Genet 10: e1004820.

\section{Discussion with Reviewers}

Oliver Gardner: The authors have taken the unusual approach of creating multiple defects in each animal, greatly reducing the number of animals that may have otherwise been used. Based on their experience, do the authors have any comments or reflections on this approach or advice for other groups looking to perform similar experiments?

Authors: Our study design could be considered as a limitation, but at the same time it was an opportunity. Using a single animal for multiple models, all studying the same biological process (endochondral ossification), can be a confounding factor, as the researchers have no control on factors that might influence each other. This could be addressed by using different animals for each model. However, considering inter-animal variation when using different animals for different models, we would never have been able to make the comparison as accurate as we did using this combined model. Moreover, the potential influence of one factor on the other would be expected to be similar in each rabbit. The only difference between the two groups was administration of celecoxib, which was the variable we aimed to test.

When studying the influence of one variable (for instance a medication) on a biological process in vivo (such as endochondral bone fracture healing), it might be worthwhile to always keep in mind that in the same animal (a) similar biological process(es) is/are occurring or can be studied as well (such as endochondral growth plate development and ectopic cartilage formation). This is relevant for multifactorial situations, for example studying the effect of NSAIDs on bone fracture healing in a growing child. The use of NSAIDs will not only affect bone fracture healing, but potentially also growth plate development. Analysis of similar biological processes within one animal will not only result in relevant data regarding the biological process (endochondral ossification) itself but results can additionally be applied to a broader relevant clinical setting, while at the same time reducing the number of animals needed to study these processes separately.

Michael Pest: While beyond the scope of this manuscript, how much influence might behavioural changes have on this study? Changes in general activity, joint loading, gait, pain perception, etc. were not evaluated in this study and may have affected the final outcomes.

Authors: Using the ulna and both tibia in this experiment did not result in detectable weight loss (data shown in Fig. 1) and gross behavioural changes, as observed by the researchers while taking daily care of the animals. Although specific small changes may have been left un-noted, we expected that potential behavioural changes would have had no significant effect on the experimental outcomes reported in our manuscript.

Michael Pest: Considering the impressive suppression of PEO by celecoxib, should high-dose NSAIDs treatment be considered for studying the treatment of heterotopic ossification due to trauma, osteochondromas or other similar diseases?

Authors: It is unknown whether the effects of celecoxib, which we report here, would also be observed when lower concentrations would have been used or with other NSAIDs. However, NSAIDs are indeed already used to prevent heterotopic ossification (HO) after hip arthroplasty (Shehab et al., 2002). Factors that are described to influence heterotopic ossification development are prostaglandins (Balboni et al., 2006; Shehab et al., 2002). Urinary excretion of $\mathrm{PGE}_{2}$ is a recommended indicator of early $\mathrm{HO}$ and the $\mathrm{PGE}_{2}-$ blocker NSAID indomethacin is highly effective in avoiding HO formation (Brooker et al., 1973; Grohs et al., 2007; Schurch et al., 1997). Whether (a high dose of) celecoxib could be beneficial in the prevention of heterotopic ossification, caused by other events, such as trauma or a period of immobilisation, was not a topic of our study but is very well possible. We (and others) have already shown that the NSAIDs celecoxib and indomethacin negatively influence endochondral ossification in vitro (Caron et al., 2017; Welting et al., 2011). Furthermore, local, instead of systemic administration of celecoxib, may differently influence the course of chondrogenic differentiation, but this will also be topic of our future studies. 


\section{Additional References}

Balboni TA, Gobezie R, Mamon HJ (2006) Heterotopic ossification: pathophysiology, clinical features, and the role of radiotherapy for prophylaxis. Int J Radiat Oncol Biol Phys 65: 1289-1299.

Brooker AF, Bowerman JW, Robinson RA, Riley LH, Jr. (1973) Ectopic ossification following total hip replacement. Incidence and a method of classification. J Bone Joint Surg Am 55: 1629-1632.

Caron MMJ, Emans PJ, Cremers A, Surtel DAM, van Rhijn LW, Welting TJM (2017) Indomethacin induces differential effects on in vitro endochondral ossification depending on the chondrocyte's differentiation stage. J Orthop Res 35: 847-857.
Grohs JG, Schmidt M, Wanivenhaus A (2007) Selective COX-2 inhibitor versus indomethacin for the prevention of heterotopic ossification after hip replacement: a double-blind randomized trial of 100 patients with 1-year follow-up. Acta Orthop 78: 95-98.

Schurch B, Capaul M, Vallotton MB, Rossier AB (1997) Prostaglandin E2 measurements: their value in the early diagnosis of heterotopic ossification in spinal cord injury patients. Arch Phys Med Rehabil 78: 687-691.

Shehab D, Elgazzar AH, Collier BD (2002) Heterotopic ossification. J Nucl Med 43: 346-353.

Editor note: The scientific editor for this paper was Mauro Alini. 